\title{
Protective effects and mechanisms of Ndfipl on SH-SY5Y cell apoptosis in an in vitro Parkinson's disease model
}

\author{
L.F. Xing ${ }^{1,2}$, H.P. Guo ${ }^{3}$, D.T. Wang ${ }^{4}$, L.H. Sun $^{5}$ and S.Y. Pan ${ }^{1}$ \\ ${ }^{1}$ Department of Neurology, Nanfang Hospital, Southern Medical University, \\ Guangzhou, Guangdong, China \\ ${ }^{2}$ Department of Neurology, China Ordnance Northern Heavy Group Hospital, \\ the Third Affiliated Hospital of Baotou Medical College, Baotou, \\ Inner Mongolia, China \\ ${ }^{3}$ Department of Physical Examination, Binzhou People's Hospital, \\ Binzhou, Shandong, China \\ ${ }^{4}$ Department of Thoracic Surgery, Central Hospital, Baotou, Inner Mongolia, \\ China \\ ${ }^{5}$ Department of Neurology, \\ The Affiliated Hospital of Inner Mongolia Medical University, Hohhot, \\ Inner Mongolia, China \\ Corresponding author: S.Y. Pan \\ E-mail: gd_suyaopan@163.com
}

Genet. Mol. Res. 15 (2): gmr.15026963

Received October 5, 2015

Accepted December 29, 2015

Published April 25, 2016

DOI http://dx.doi.org/10.4238/gmr.15026963

\begin{abstract}
The aim of the current study was to examine the protective effects and mechanisms of Ndfipl on neurocytes in an experimental in vitro Parkinson's disease model induced by $\mathrm{MPP}^{+}$. The cell model was developed with dominant negative expression and suppressed expression of Ndfipl by means of transient transfection of Ndfipl-dominant negative and -inhibitory vectors. In total, four different Ndfipl cell models were established. Different methods were used to analyze the cells. The MTT method was used to detect the effect of
\end{abstract}


Ndfipl on the survival rate and apoptosis of the cells induced by MPP . We further studied the roles of Ndfipl in inhibiting $\mathrm{MPP}^{+}$-induced $\mathrm{SH}-$ SY5Y apoptosis, protection, and ubiquitination of SH-SY5Y cells. Our results showed that Ndfipl reduced apoptosis and improved cell survival rate, indicating that Ndfipl has a neuroprotective effect. Furthermore, we found that Ndfipl binds to Nedd4-1, and that increased expression of Ndfipl significantly reduced Itch expression. We also found that increased ubiquitination played a role in Ndfipl-mediated processes, and that Ndfipl and $\alpha$-synuclein interact. Additionally, the expression of Ndfipl reduced expression of $\alpha$-synuclein. In conclusion, Ndfipl plays a significant role in protecting SH-SY5Y cells in in vitro Parkinson's disease models.

Key words: Ndfipl; Parkinson's disease; Apoptosis; Ubiquitination

\section{INTRODUCTION}

Parkinson's disease (PD) is a common central nervous system degenerative disease of the elderly. The global incidence of PD is approximately $1 \%$ in individuals over 60 years old (Hara and Snyder, 2007). Additionally, morbidity associated with PD increases with age. This disease severely influences movement ability and quality of life of affected individuals, and hence has a high-disability rate. As such, PD necessitates life-long management, which causes significant social and economic burdens on patients (Hara and Snyder, 2007; Lim, 2007). To date, the understanding of the pathogenesis of PD remains limited. Recent evidence has demonstrated that a defect in protein degradation ability is one of the important factors in the onset of PD. Significant importance has always been placed on drug therapies for the management of PD; however, current medications in use today have serious issues, including undesirable side effects and insignificant therapeutic effects (Maemondo, 2012; Goldman and Holden, 2014). Therefore, safe and curative therapeutics that protect neurons, and that prevent the apoptosis of neurocytes have been a focus of research in the neuroscience field. Along these lines, the Nedd4 family-interacting protein 1 (Ndfipl) is a potentially promising therapeutic protein that can protect neurons.

Ndfipl, also called N4WBP5, is a trans-membrane protein that contains 221-amino acid residues and has a molecular weight of approximately $26 \mathrm{kDa}$. It binds to Hect family proteins such as Nedd4 in the WW-PY manner through the PY motif (Ferreira et al, 2011; Wang et al., 2012; Howitt et al., 2014; Martínez-Pacheco et al., 2014). The presence of PY motifs in Ndfipl has a direct relationship with its functions, and the use of the dominant-negative mutant (mutation of two PY motifs) of Ndfipl has contributed to research elucidating its functions and mechanism of action. However, there has currently been no in-depth research on the functions of Ndfipl, although research has indicated that it can influence multiple-intracellular processes. Particularly, it has been shown that Ndfipl plays a significant role in protecting neurocytes (Qiu et al, 2011). Ndfipl and Nedd4 can jointly participate in transport and degradation of certain proteins via the ubiquitin-dependent pathway, which may subsequently influence neurocyte apoptosis. The goals of the current study were to better understand the pathogenesis of PD and the relationship between Ndfipl and PD, and to explore new methods for managing this 
disease. To accomplish these goals, we utilized the human neuroblastoma SH-SY5Y cell line cultured with 1-methyl-4-phenyl-1,2,3,6-tetrahydropyridine (MPP $\left.{ }^{+}\right)$as an in vitro model of $\mathrm{PD}$, in which the expression of Ndfipl was controlled with a lentiviral expression vector. We then investigated the role of Ndfipl in neurocyte protection in this in vitro experimental $\mathrm{MPP}^{+}$induced PD model, and examined the mechanism of action of Ndfipl in neurocyte protection, which in turn provides an experimental basis for future clinical studies into the use of Ndfipl for the treatment of PD and alleviation of its symptoms.

\section{MATERIAL AND METHODS}

\section{Main reagents and instruments}

The following cells and reagents were used in this study: human embryonic kidney 293T cells (Shanghai Laboratory Animal Center, Chinese Academy of Sciences); SH-SY5Y cells (Institute of Basic Medical Sciences, Peking Union Medical College); MPP ${ }^{+}$, 4-hydroxy tamoxifen (4HT), ploybrene, puromycin, and hygromycin B (Sigma-Aldrich, Seelze, Germany); fetal bovine serum (FBS), primary culture FBS, DMEM high-glucose culture medium, DMEM high-glucose culture medium with HEPES, trypsin, PBS, and double-antibody penicillinstreptomycin (Wisent Biotechnology Nanjing Co., Ltd., Ninjang, China); Lipofectamine 2000 transfection reagent kits (Invitrogen, Carlsbad, CA, USA); Effectene Transfection Reagent (QIAGEN, Hilden, Germany); centrifuge (centrifuge 5415D), refrigerated centrifuge (5475R), and ultraviolet spectrophotometer (Eppendorf, Hamburg, Germany); DNA electrophoresis apparatus (Danyang No. 1 Wireless Factory, Danyang, China); DNA electrophoresis tank (Model DYCP-32 electrophoresis tank) (Beijing Bayi Instrument Plant, Beijing, China); Western blot electrophoresis equipment (Bio-Rad Company, Hercules, CA, USA).

\section{Cell culture and plasmid extraction}

The supercompetent bacteria preparation kit (Biyuntian Company, Beijing, China) was used to prepare competent cells. DH5 $\alpha$ bacteria were applied onto the LB plate, cultured overnight at $200 \mathrm{rpm}$ at $37^{\circ} \mathrm{C}$ for $14-16 \mathrm{~h}$. Then, $300 \mu \mathrm{L}$ fresh overnight bacteria were inoculated and cultured for $2-3 \mathrm{~h}$. When the $\mathrm{OD}_{600}$ reached $0.4-0.6$, the bacterium solution was cooled in an ice bath. The bacteria were then centrifuged, gently resuspended with $20 \mathrm{~mL}$ precooled supercompetent preparation reagents A and B, precipitated, and cooled in an ice-bath.

For transformation, $1 \mu \mathrm{L}$ plasmid was added to $100 \mu \mathrm{L}$ competent cells. Single colonies were shaken. Then, a plasmid DNA mini-extraction kit was used to extract the plasmid. The 7736 and 8599 plasmids were digested with $\mathrm{Xbal}$ and NE2, and electrophoresed on agarose gel (TaKaRa Biology Co., Ltd., Dalian, China). The electrophoresis results were imaged and photographed.

\section{MTT colorimetric experiment}

SH-SY5Y cells were cultured in an incubator containing $5 \% \mathrm{CO}_{2}$ at $37^{\circ} \mathrm{C}$ until the plate (96-well microplate) was fully covered with cells. The cells were cultured for approximately $20 \mathrm{~h}$ after the prepared MTT solution with a fixed concentration gradient was added. The 
cells were cultured for another $4 \mathrm{~h}$ after MTT addition. The liquid culture medium was then pipetted off carefully, and then the plates were vibrated on a shaking table at low speed for 10 min after the addition of dimethyl sulfoxide, allowing for complete dissolution of the crystal substance. Light absorption values of all wells were measured at $490 \mathrm{~nm}$ with an ELISA microplate reader, including experimental wells, zero adjustment wells (culture medium, MTT, and dimethyl sulfoxide), and control wells (cells, medicine dissolution media at the same concentration, culture medium, MTT, and dimethyl sulfoxide).

\section{Flow cytometric detection of apoptosis}

SH-SY5Y cells were digested with pancreatic enzyme containing no EDTA and collected (centrifuged at $2000 \mathrm{rpm}$ for $5 \mathrm{~min}$ ). The cells were washed twice with PBS (centrifuged at $2000 \mathrm{rpm}$ for $5 \mathrm{~min}$ between washes) and 2-5 $\times 10^{5}$ cells were collected. The cells were suspended and well mixed after the addition of $500 \mu \mathrm{L}$ binding buffer. The cells were well mixed after the addition $5 \mu \mathrm{L}$ Annexin V-FITC and $5 \mu \mathrm{L}$ propidium iodide, and then were incubated for $15 \mathrm{~min}$ at room temperature away from light. The cells were then subjected to flow cytometry. The fluorescence of Annexin V-FITC was detected through the FL1 channel, and propidium iodide fluorescence was detected with the FL2 or FL3 channel.

\section{Co-immunoprecipitation}

After 24-48 $\mathrm{h}$ transfection, the SH-SY5Y cells were harvested. The supernatants were then collected after cell lysis. A small volume of lysate was taken for western blot analysis. The remaining lysate was shaken slowly and incubated overnight at $4^{\circ} \mathrm{C}$ after the addition of appropriate antibodies. Then, pretreated protein A agarose beads were added to the cell lysate. The cells were shaken slowly and incubated for $4 \mathrm{~h}$ enabling the antibodies to sufficiently bind to the protein A agarose beads. Then, the mixture was centrifuged at $3000 \mathrm{rpm}$ for $3 \mathrm{~min}$ at $4^{\circ} \mathrm{C}$. The supernatant was pipetted off slowly. The agarose beads were washed with $1 \mathrm{~mL}$ lysis solution. After the addition of $2 X$ SDS loading buffer, the bead mixtures were boiled for $5 \mathrm{~min}$ before western blot analysis.

\section{Preparation of total cellular protein lysate, protein quantification, extraction of cellular protein, and western blot assay}

The $293 \mathrm{~T}$ cells were cultured for $2 \mathrm{~h}$ and transfected when the confluency reached over 70\%. The Effectene Transfection Reagent kit was used for transfection (QIAGEN). The vectors and Ndfipl encoding pEGFP-C1 plasmids necessary for lentivirus packaging were co-transfected into the $293 \mathrm{~T}$ packaging cells. The cells were observed for green fluorescence with a fluorescence microscope after 24-48 h. The 293T cells were infected and screened after the addition of antibiotics. Then, 4HT was added to adjust the expression level of the Ndfipl protein when the cells grew to $70-80 \%$ confluency. 4HT (100 nM) was used for vector induction. GEVl6 was able to enter the cell nuclei and bound to $5 \mathrm{x}$ UAS, thus promoting over-expression of Ndfipl after GEV16 was expressed. The cells were lysed $24 \mathrm{~h}$ after 4HT induction. The changes in Ndfipl protein expression were analyzed via western blot. The 8887 
plasmid was transiently transfected with the stable cell strains generated above. After many passages, the stably transduced cells were re-screened with puromycin and hygromycin B. The changes in Ndfipl protein expression were then detected with western blot to ensure the reliability and stability of the inducible expression system. Four different cell models were developed, including Ndfipl endogenous expression (WT), overexpression (4HT induction), dominant-negative expression (4HT induction and dominant-negative vector), and suppression expression (pGIPZ shRNA for Ndfipl transient transfection). The expression of the Ndfipl protein was preliminarily determined.

\section{Statistical analysis}

All data were analyzed by SPSS 17.0 (SPSS Inc., Chicago, IL, USA) and subjected to normality tests by 1 -sample K-S, and those that were normally distributed were compared. The eligible data were analyzed by one-way ANOVA LSD program or Tambane's T2 method. The data are reported as means \pm standard error, and the means were compared by Student $t$-tests. The data that did not conform to a normal distribution with variance heterogeneity were compared by the Wilcoxon rank sum test, and reported as means \pm interquartile range. $\mathrm{P}<0.05$ was considered statistically significant.

\section{RESULTS}

\section{Cell culture and plasmid extraction}

The cells were successfully cultured and the plasmids were extracted after the experiment. The results of the plasmid agarose gel electrophoresis detection are shown in Figure 1A. Various viral packaging vectors and relevant plasmids complied with the experimental requirements in terms of concentration and quality. Acquisition of these vectors laid a foundation for establishment of four different cell models by lentiviral transduction. The 8599 and 7736 plasmids were subjected to double-enzyme digestion. The DNA molecules containing Ndfipl were identified on the basis of the molecular weight of the DNA marker (Figure 1B). Based on the expression of Ndfipl after the 293T cells were transiently transfected with Ndfipl (Figure 1C), it was determined that there was a highexpression level of Ndfipl, further indicating that the 8599 plasmid encoded for the protein of interest.

\section{Establishment of the four cell models}

A small amount of green fluorescence was observed in the 293T cells transfected with the Ndfipl lentiviral vector $24 \mathrm{~h}$ after transfection (Figure 2A and B); a large amount of green fluorescence was observed in the 293T cells transfected with the GEV16 lentiviral vector (Figure 2C and D); both of which indicated that the transfection had high efficiency. The supernatants from the two types of cells were collected and added to the SH-SY5Y cells. The positive cells were obtained after screening. Monoclonal cells were selected and further cultured. Stable cell strains with controllable expression of Ndfipl were validated with a western blot assay (Figure 2E). 
A

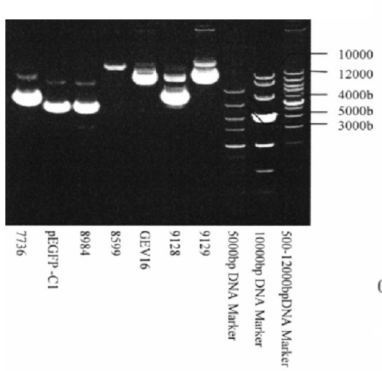

B

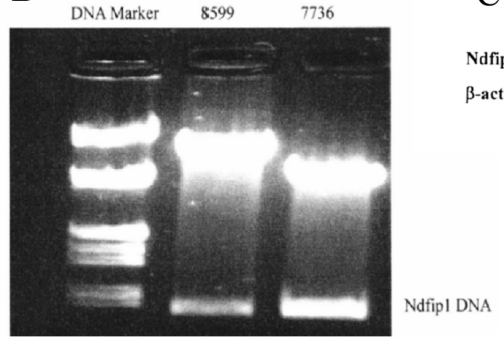

$\mathrm{C}$

Ndfip1

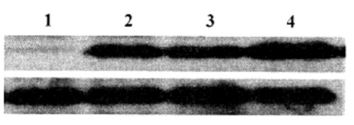

Figure 1. Results of plasmid agarose gel electrophoresis. A. pEGFP-C1 and 8984 are plasmids containing green fluorescence protein gene; 7736 and 8599 are the plasmids containing the Ndfipl gene; GEVl6 is the plasmid that expresses the GEVl6 switchable protein; 9128 and 9129 are the plasmids that express the viral coat protein; 8420 is the plasmid containing Ndfipl-dominant negative vector; and 8887 is the plasmid specific to the inhibitive characteristic of Ndfipl. B. The Ndfipl DNA fragments after the plasmid 8599/7736 was subject to double-enzyme restriction are presented. C. The expression of Ndfipl after the 293T cells were transiently transfected is presented. Lane 1 is the normal group; lane 2 is the group transfected with plasmid 7736; lane 3 is the group transfected with plasmid 8599; and lane 4 is the group with packaging viral transfection plasmid 8599 .
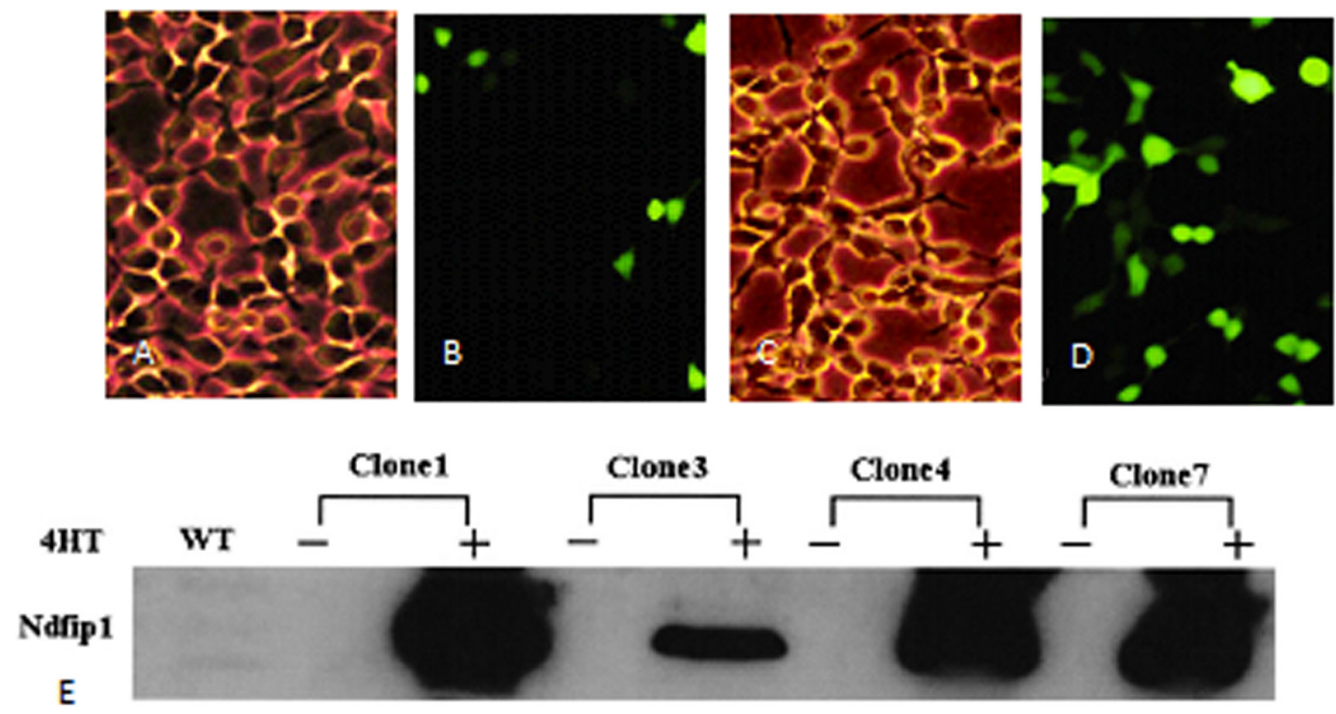

Figure 2. Morphology of 293T cells transfected with lentiviral vectors A and B present the morphology of the 293T cells $24 \mathrm{~h}$ after transfection with pF5 x UAS mm Ndfipl C-Flag SV40 Puro. A. Cellular morphology under the visible light. B. Cellular morphology under the green fluorescence state. C. and D. Morphology of the 293T cells 24 $\mathrm{h}$ after transfection with pFU Gal4 ER VPl6 PGK promoter Hygro (GEV16). C. Cellular morphology under visible light. D. State of excited green fluorescence. Both are the same field of view. E. Identification of the clones of the SH-SY5Y cells with controlled expression of the Ndfipl gene. Clones 1, 3, 4, and 7 can express Ndfipl through 4HT induction. Clone 1 serves as the cell strain in the subsequent experiments and is marked as SY5Y-N cell.

The Ndfipl-dominant negative vector and pGIPZ shRNA for Ndfipl vector were transiently transfected into the SY5Y-N cells to obtain two additional cell models, i.e., the Ndfipl-dominant negative expression model and the suppression expression model, which 
were marked as SY5Y-D and SY5Y-I cells, respectively. Figure 3 shows that a large amount of the Ndfipl protein was expressed in SY5Y-N and SY5Y-D cells, while a small amount of the Ndfipl protein was expressed in SY5Y-I cells.
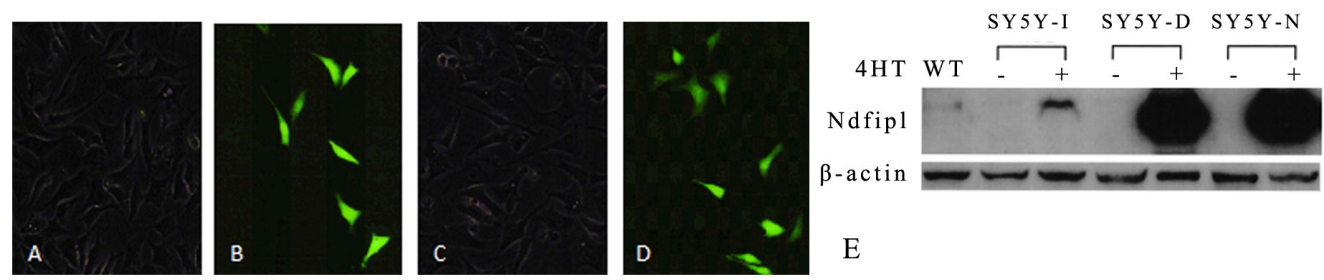

Figure 3. Morphology of cells transfected with dominant-negative vector and shRNA. A. and B. Morphology of the SY5Y cells $24 \mathrm{~h}$ after transfection with pFU mm BP5 Y42A67A EGFP SV40 Puro W (Ubiquitin Promoter) (8420). A. Cellular morphology under the visible light. B. Green fluorescence state. Both are the same field of view. C. and D. Morphology of the SY5Y cells $24 \mathrm{~h}$ after transfection with pGIPZ shRNA for Ndfipl (8887). C. Cellular state under visible light. D. Excited fluorescence state. Both were the same field of view. E. Induced expression of the Ndfipl protein in four cell models. A large amount of the Ndfipl protein was expressed in SY5Y-N and SY5Y-D cells while only a small amount of the Ndfipl protein was expressed in SY5Y-I cells.

\section{Effect of different treatment methods on the cell survival rate of the four cell models}

Cells from the four cell models were either left untreated or treated with $\mathrm{MPP}^{+}$. The expression of Ndfipl was induced by the addition of 4HT. The MTT method was used to detect the effect of Ndfipl on the survival rate of the cells induced by $\mathrm{MPP}^{+}$. As shown in Figure 4A, $\mathrm{MPP}^{+}$treatment caused a similar cell mortality rate in the four cell models. The survival rate of the SY5Y-N cells was slightly higher due to a low level of Ndfipl expression, indicating that $\mathrm{MPP}^{+}$treatment could induce SH-SY5Y cells to form PD cell models. The expression of Ndfipl was increased in the SY5Y-N cells after induction with 4HT, which significantly reversed apoptosis after the addition of $\mathrm{MPP}^{+}$. There was also a significant difference between the group treated with both $\mathrm{MPP}^{+}$and $4 \mathrm{HT}$ and the group treated with $\mathrm{MPP}^{+}$alone and other groups with the addition of 4HT $(\mathrm{P}<0.05)$. Similar to the WT-SY5Y cells, the survival rate of the SY5Y-D cells was barely changed compared with that of the cells in the group with the addition of $\mathrm{MPP}^{+}$alone. The cell survival rate of SY5Y-I improved owing to low expression levels of Ndfipl, but no significant difference was observed $(\mathrm{P}>0.05)$.

\section{Effect of different treatment methods on apoptosis of the four cell models}

Figure 4B presents the flow cytometry results after different treatments of the four cell models. $\mathrm{MPP}^{+}$treatment caused a high apoptosis rate in the four cell models, and there were no significant differences among them. The induced expression of Ndfipl in SY5Y-N cells by $4 \mathrm{HT}$ significantly reduced apoptosis from $\mathrm{MPP}^{+}$treatment. There was also a significant difference between cells treated with both $\mathrm{MPP}^{+}$and $4 \mathrm{HT}$ and cells treated with $\mathrm{MPP}^{+}$alone and the other groups with addition of 4HT $(\mathrm{P}<0.05)$. The WT-SY5Y cells had a similar apoptosis rate to the SY5Y-D Ndfipl-dominant negative cells (mutation of two PY motifs). The apoptosis rate of the SY5Y-D cells was barely changed compared with the cells treated 
A

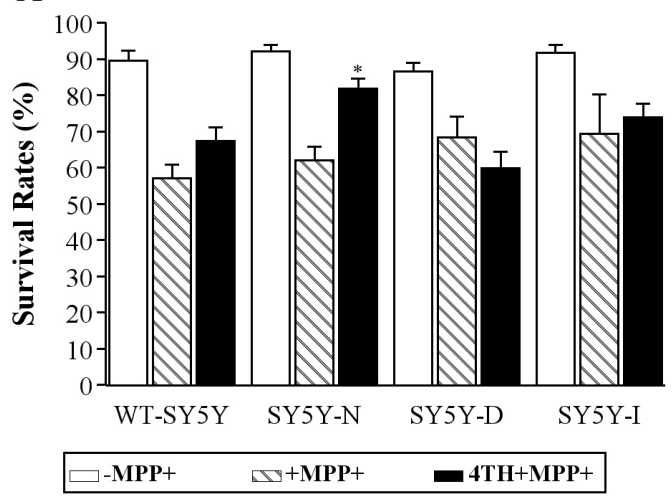

$\mathrm{B}$

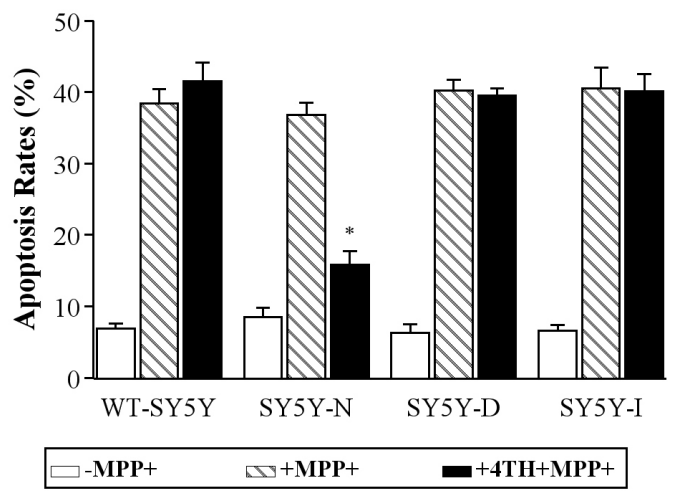

Figure 4. Effects of different treatment methods on the survival rates and apoptosis rates. A. Effects of different treatment methods on the cell survival rates of the four types of cell models. *Means with significant differences based on a comparison with the group with $\mathrm{MPP}^{+}$added and other groups with $4 \mathrm{HT}$ added $(\mathrm{N}=5 ; \mathrm{P}<0.05)$. B. Effects of 24-h treatment using different methods on cell apoptosis of the four types of cell models. *Means with significant differences based on a comparison with the group with $\mathrm{MPP}^{+}$added and other groups with 4HT added $(\mathrm{N}=5 ; \mathrm{P}<0.05)$.

with $\mathrm{MPP}^{+}$alone. The apoptosis rate of the SY5Y-I cells decreased due to the presence of low levels of Ndfipl expression, but no significant difference was observed $(\mathrm{P}>0.05)$. Thus, it was clear that apoptosis increased significantly and the cell survival rate decreased significantly after induction with $\mathrm{MPP}^{+}(0.3 \mathrm{mM})$. Moreover, while $\mathrm{MPP}^{+}$had certain damaging effects on the SH-SY5Y cells, Ndfipl had certain protective effects on the damaged cells. Additionally, the cell survival rate was high in Ndfipl-expressing cells. Taken together, these data indicate that Ndfipl had a protective effect on SH-SY5Y cells. Furthermore, the protective effect was closely associated with the stability of the two PY motifs of Ndfipl.

\section{Role of Ndfipl in inhibiting the apoptosis of the SH-SY5Y cells induced by MPP ${ }^{+}$}

The two Hect family proteins, Nedd4-1 and Itch, were detected following coimmunoprecipitation via western blot. Apoptosis was induced by the removal of growth factors. Immunoprecipitation was accomplished with an antibody against Ndfipl. Detection was performed with an Nedd4-1 antibody. As seen in Figure 5A, the role of Ndfipl in protecting cells may be caused by binding to Nedd4-1. Nedd4-1 is an ubiquitin E3 ligase. Thus, Ndfipl may recruit many proteins to bind to Nedd4, and further cause ubiquitination of these proteins thus regulating apoptosis. This result is consistent with increased ubiquitination caused by Ndfipl. This also indicates that Ndfipl may cause ubiquitination of many proteins through bridging, and hence may play an important role in many cells.

\section{Protective and ubiquitination roles of Ndfipl in SH-SY5Y cells}

Next, we sought to clarify whether the role of Ndfipl in inhibiting apoptosis of neurocytes was accompanied with increased ubiquitination. Apoptosis was induced by the removal of grow factors. The ubiquitination process was detected with anti-ubiquitin 
antibodies. The results are shown in Figure 5B. The results indicate that the role of Ndfipl in protecting cells is accompanied with increased ubiquitination of many proteins, suggesting that the molecular mechanism of that Ndfipl involves the ubiquitination processes.

\section{Interaction between Ndfipl and partial PD causative genes}

Much evidence has indicated that PD and other neurodegenerative diseases may be protein degradation disorders. The causative genes of familial PD are closely associated with the ubiquitin-proteasome system. In the present study, the interaction between Ndfipl and $\alpha$-synuclein was detected through western blot after immunoprecipitation (Figure 5C). As demonstrated in Figure 5, the amount of $\alpha$-synuclein detected decreased with decreasing expression of Ndfipl, indicating that Ndfipl and $\alpha$-synuclein interact.
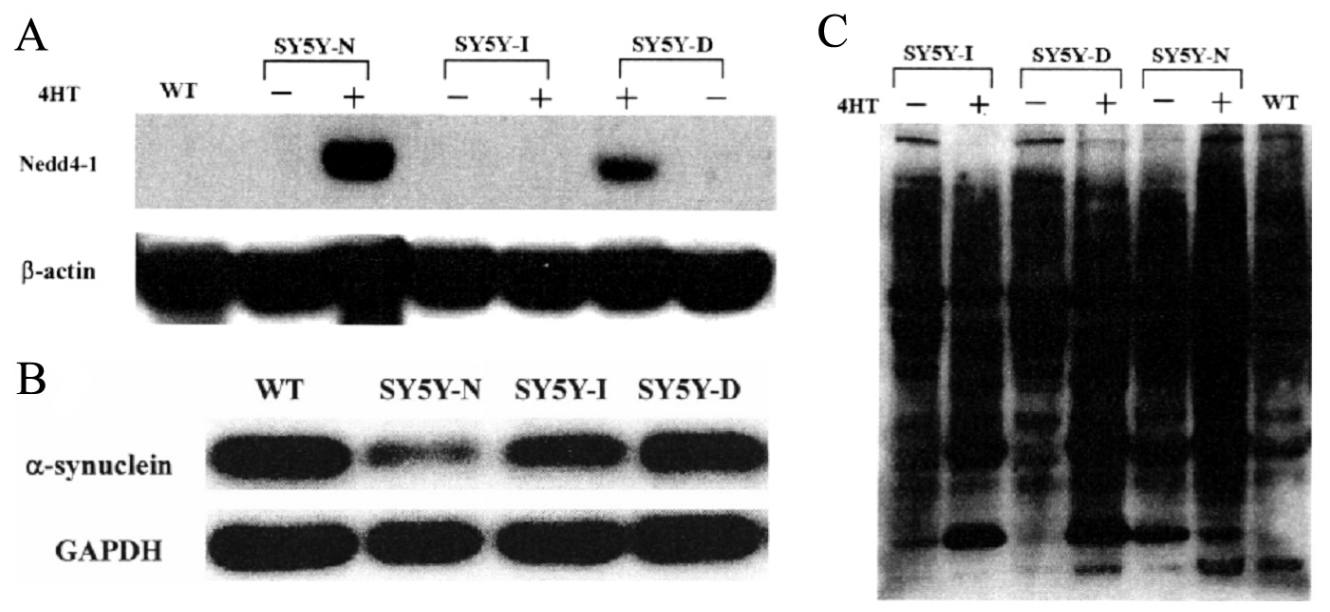

Figure 5. A. Ndfipl was bound to Nedd4-1 in protecting cells. B. Role of Ndfipl in protecting cells was accompanied with increased of ubiquitination of many proteins. C. Expression of Ndfipl caused reduced expression of $\alpha$-synuclein.

\section{DISCUSSION}

Currently, the causes of PD remain unclear. In order to gain a deeper understanding of the causes, pathological mechanisms, metabolic biochemistry, and treatment of $\mathrm{PD}$, it is vital to develop adequate models of PD. At present, there are many animal models available, and 6-OHDA and MPTP models are the two most common.

MPTP is a synthetic heroin intermediate. It can penetrate the blood brain barrier and convert to toxic $\mathrm{MPP}^{+}$under the action of monoamine oxidase $\mathrm{B} . \mathrm{MPP}^{+}$is very similar to dopamine in chemical structure, and can act on SNpc through dopamine transporter to further recruit $\mathrm{MPP}^{+}$to the mitochondria; thus, impeding the role of respiratory chain enzyme complex I, energy crisis, and cell death (Midde et al., 2013; Velázquez-Sánchez et al., 2013; Dehnes et a., 2014; Schwarz et al., 2014). Additionally, $\mathrm{MPP}^{+}$is able to inhibit the activity of tyrosine hydroxylase, thus reducing the synthesis of dopamine. Moreover, $\mathrm{MPP}^{+}$can cause substantial reductions in substantia nigra cytons, corpus striatum teleneurons, and dopamine 
transmitters (Ono et al., 2009). Dopamine is an inhibitory neurotransmitter, and PD symptoms will occur if dopamine's inhibitory effect is excessively decreased. In the current study, cell models of PD were successfully established with human neuroblastoma cells induced and cultured with $\mathrm{MPP}^{+}$.

The cells were treated by addition of $\mathrm{MPP}^{+}$or no addition of $\mathrm{MPP}^{+}$. The expression of Ndfipl was induced by the addition of 4HT. The MTT and flow cytometry results indicate that increased expression of Ndfipl can significantly reduce cell death, and can protect the neurocytes. Further experimental results showed that Ndfipl interacts with the Hect family proteins Nedd4-1 and Itch during inhibition of apoptosis of MPP ${ }^{+}$-induced SH-SY5Y cells. Ndfipl binds to Nedd4-1 as it exerts its functions. Increased expression of Ndfipl caused a significant decline in Itch. However, little is known about Itch possibly due to ubiquitination. Ubiquitination and further degradation of many proteins may be associated with Ndfipl/ Nedd4 due to the specific binding between the Hect family proteins including Ndfipl and Nedd4, the latter of which is an ubiquitin ligase. The ubiquitination process was evaluated with anti-ubiquitin antibodies indicating that the molecular mechanism of Ndfipl involves the ubiquitination of many proteins.

The causative genes of familial PD are closely associated with the ubiquitinproteasome system (Nevanlinna and Kallioniemi, 1999; Ariga et al., 2013; Fujishiro et al., 2013). Currently, such genes include $\alpha$-synuclein, Parkin, and ubiquitin carboxyl hydrolase LI. Much evidence indicates that $\alpha$-synuclein may be involved in disturbing the storage and release of dopamine, increasing oxidative stress levels, and influencing the signal transmission in PD pathogenesis. Substantial aggregation of $\alpha$-synuclein leads to the formation of globules. The dysfunction of the ubiquitin-proteasome triggers PD due to decreased ability to remove the aggregated protein. Thus, the expression of $\alpha$-synuclein was investigated in the current study. The results show that the expression of $\alpha$-synuclein exhibits a decreasing trend with decreased expression of Ndfipl, indicating that Ndfipl and $\alpha$-synuclein interact.

The mechanisms of action of Ndfipl may involve many proteins and signal channels, apoptosis inhibition, as well as ubiquitination and transport of proteins. Further in-depth analyses are required to determine the downstream proteins of Ndfipl that directly or indirectly interact with, how to mediate new substrates for binding to Nedd4, what signal channels Ndfipl participates with, whether Ndfipl plays the same role in tumor or other cells, and the potential use of Ndfipl in gene treatment.

\section{Conflicts of interest}

The authors declare no conflict of interest.

\section{REFERENCES}

Ariga H, Takahashi-Niki K, Kato I, Maita H, et al. (2013). Neuroprotective function of DJ-1 in Parkinson's disease. Oxid. Med. Cell. Longev. 2013: 683920. http://dx.doi.org/10.1155/2013/683920

Dehnes Y, Shan J, Beuming T, Shi L, et al. (2014). Conformational changes in dopamine transporter intracellular regions upon cocaine binding and dopamine translocation. Neurochem. Int. 73: 4-15. http://dx.doi.org/10.1016/j. neuint.2014.02.003

Ferreira MA, Matheson MC, Duffy DL, Marks GB, et al. (2011). Identification of IL6R and chromosome 11q13.5 as risk loci for asthma. Lancet 378: 1006-1014. http://dx.doi.org/10.1016/S0140-6736(11)60874-X 
Fujishiro H, Imamura AY, Lin WL, Uchikado H, et al. (2013). Diversity of pathological features other than Lewy bodies in familial Parkinson's disease due to SNCA mutations. Am. J. Neurodegener. Dis. 2: 266-275.

Goldman JG and Holden S (2014). Treatment of psychosis and dementia in Parkinson's disease. Curr. Treat. Options Neurol. 16: 281. http://dx.doi.org/10.1007/s11940-013-0281-2

Hara MR and Snyder SH (2007). Cell signaling and neuronal death. Annu. Rev. Pharmacol. Toxicol. 47: 117-141. http:// dx.doi.org/10.1146/annurev.pharmtox.47.120505.105311

Howitt J, Gysbers AM, Ayton S, Carew-Jones F, et al. (2014). Increased Ndfip1 in the substantia nigra of Parkinsonian brains is associated with elevated iron levels. PLoS One 9: e87119. http://dx.doi.org/10.1371/journal.pone.0087119

Lim KL (2007). Ubiquitin-proteasome system dysfunction in Parkinson's disease: current evidence and controversies. Expert Rev. Proteomics 4: 769-781. http://dx.doi.org/10.1586/14789450.4.6.769

Maemondo M (2012). Timing the change of chemotherapy for non-small cell lung cancer. Gan To Kagaku Ryoho 39: 1316-1319.

Martínez-Pacheco M, Hidalgo-Miranda A, Romero-Córdoba S, Valverde M, et al. (2014). MRNA and miRNA expression patterns associated to pathways linked to metal mixture health effects. Gene 533: 508-514. http://dx.doi.org/10.1016/j. gene.2013.09.049

Midde NM, Huang X, Gomez AM, Booze RM, et al. (2013). Mutation of tyrosine 470 of human dopamine transporter is critical for HIV-1 Tat-induced inhibition of dopamine transport and transporter conformational transitions. $J$. Neuroimmune Pharmacol. 8: 975-987. http://dx.doi.org/10.1007/s11481-013-9464-6

Nevanlinna H and Kallioniemi OP (1999). Susceptibility genes of familial breast cancer in Finland. Duodecim 115: 23652374.

Ono S, Hirai K and Tokuda E (2009). Effects of pergolide mesilate on metallothionein mRNAs expression in a mouse model for Parkinson disease. Biol. Pharm. Bull. 32: 1813-1817. http://dx.doi.org/10.1248/bpb.32.1813

Qiu X, Chen GH and Wang T (2011). Effects of huanglian jiedu decoction on free radicals metabolism and pathomorphism of the hippocampus in App/PS1 double transgenic mice. Zhongguo Zhong Xi Yi Jie He Za Zhi 31: 1379-1382.

Schwarz M, Jandová K, Struk I, Marešová D, et al. (2014). Low dose domoic acid influences spontaneous behavior in adult rats. Physiol. Res. 63: 369-376.

Velázquez-Sánchez C, García-Verdugo JM, Murga J and Canales JJ (2013). The atypical dopamine transport inhibitor, JHW 007, prevents amphetamine-induced sensitization and synaptic reorganization within the nucleus accumbens. Prog. Neuropsychopharmacol. Biol. Psychiatry 44: 73-80. http://dx.doi.org/10.1016/j.pnpbp.2013.01.016

Wang Y, Tong X and Ye X (2012). Ndfip1 negatively regulates RIG-I-dependent immune signaling by enhancing E3 ligase Smurf1-mediated MAVS degradation. J. Immunol. 189: 5304-5313. http://dx.doi.org/10.4049/jimmunol.1201445 